\title{
USUÁRIOS DE DROGAS E TRATAMENTOS SELETIVOS NO SÉCULO XXI: ENTRE A ESTIGMATIZAÇÃO E A LEGITIMAÇÃO POR MEIO DOS CRIMES DOS PODEROSOS*
}

Felipe da Veiga Dias**

Alexandre Marques Silveira***

SUMÁRIO: Introdução; 2 O usuário de drogas como pária social: apreciações criminológicas da seletividade e discriminação social contemporânea; 3 Drogas e sua intervenção contemporânea no Brasil: a ruptura epistemológica como forma de observação dos danos sociais; 4 "Doenças" de castas e as corporações de drogas: o tratamento diferenciado na sociedade capitalista de classes; 5 Considerações Finais; Referências.

RESUMO: O presente estudo almeja analisar a estigmatização existente em relação aos usuários de drogas, bem como os efeitos dessa exclusão. A questão que orientará a pesquisa aqui proposta é: quais os mecanismos contemporâneos que garantem a manutenção da seletividade penal na política de drogas? O marco teórico é a criminologia crítica, para estabelecer uma análise crítica sobre a temática. Para isto, o método de abordagem que servirá de referência para análise das ideias, informações e resultados desta pesquisa é o método dedutivo. Quanto ao método de procedimento este será o monográfico. Concluindo que a seletividade penal na política de drogas no Brasil tem como mecanismo de manutenção o racismo estrutural e a hierarquia racial que servem como fatores invisibilizadores de danos sociais massivos ocasionados pelos poderosos.

PALAVRAS-CHAVE: Crimes dos poderosos; Danos sociais; Política de drogas; Racismo; Seletividade.

\footnotetext{
O termo crime dos poderosos é utilizado aqui para expressar condutas não necessariamente criminalizadas mas que executam massivos danos sociais, sendo usualmente englobadas ações realizadas por Estados e organizações privadas dentro das dinâmicas da acumulação capitalista e que são invisibilizados/ocultados. Essa adoção se justifica por ser mais abrangente do que mera noção de criminalidade de colarinho branco ou até mesmo por estar desvinculada na delimitação jurídica de crime. A construção criminológica pode ser verificada na exposição de Barak: BARAK, Greg. The crimes of the powerful and the globalization of crime. Revista Brasileira de Direito. v. 11, n. 2, p. 104-114, jul./dez. 2015. p. 105.

${ }^{*}$ Pós-doutorando em Ciências Criminais pela PUC/RS. Doutor em Direito pela Universidade de Santa Cruz do Sul (UNISC). Docente da Faculdade Meridional (IMED), Passo Fundo (RS), Brasil.

E-mail: felipevdias@gmail.com

${ }^{* * *}$ Mestre em Direito da Faculdade Meridional de Passo Fundo (IMED), Brasil.
} 


\title{
ILLICIT DRUG USERS AND SELECTIVE TREATMENTS IN THE $21^{\text {st }}$ CENTURY: BET WEEN STIGMATIZATION AND LEGITIMATION BY THE CRIMES OF POWERFUL PEOPLE
}

\begin{abstract}
Current stigmatization of illicit drug users and the effects of exclusion are analyzed. Which current mechanisms guarantee the maintenance of penal selectivity in policies against illicit drugs? The theoretical mark is critical criminology so that a critical analysis on the theme could be established. The deductive method is a reference for the analysis of ideas, information and results of current research, whilst the method of the procedure is monographic. Results show that penal selectivity in the illicit drug policy in Brazil is foregrounded on the maintenance of structural racism and social hierarchy, or rather, invisible factors of massive social damage caused by powerful people.
\end{abstract}

KEY WORDS: Crimes of powerful people; Social harm; Illicit drug policy; Racism; Selectivity.

\section{USUÁRIOS DE DROGAS E TRATAMENTOS SELETIVOS NO SÉCULO XXI: ENTRE A ESTIGMATIZAÇÃO E A LEGITIMAÇÃO POR MEIO DOS CRIMES DOS PODEROSOS}

RESUMO: O presente estudo almeja analisar estigmatização existente em relação aos usuários de drogas, bem como os efeitos dessa exclusão. A questão que orientará a pesquisa aqui proposta é: quais os mecanismos contemporâneos que garantem a manutenção da seletividade penal na política de drogas? O marco teórico é a criminologia crítica, para estabelecer uma análise crítica sobre a temática. Para isto, o método de abordagem que servirá de referência para análise das ideias, informações e resultados desta pesquisa é o método dedutivo. Quanto ao método de procedimento este será o monográfico. Concluindo que a seletividade penal na política de drogas no Brasil, tem como mecanismo de manutenção o racismo estrutural e a hierarquia racial que servem como fatores invisibilizadores de danos sociais massivos ocasionados pelos poderosos.

PALAVRA: Crímenes de los poderosos; Daños sociales; La selectividad; Política de drogas; Racismo. 


\section{INTRODUÇÃO}

$\mathrm{O}$ atual sistema penal não vem conseguindo cumprir com os seus objetivos declarados, gerando inúmeros processos de privação, reforçando a segregação, e não evitando a reincidência, tampouco alcançando maior efetividade no combate da criminalidade. O presente controle social tem se resumido apenas em exercer a jurisdição de uma forma seletiva e repressiva, considerando as influências e opiniões de um controle social informal, sua consciência coletiva e suas instituições que apelam por um sistema retributivo repressivo.

No Brasil, no que se refere à política de drogas, existe uma obscuridade ocasionada pela tendência puntivista e proibicionista. As averiguações penais e processuais penais das questões envolvendo a política de drogas são limitadas a julgamentos morais/seletivos, que influenciam na ampliação da criminalização de condutas. Fundamentos repressivos e interventivos têm tendência de criar estereótipos e perfis de bons e maus cidadãos, o que contribui para exclusão social, ferindo premissas éticas, jurídicas, direitos humanos básicos (como a saúde), além dos danos sociais produzidos.

Soma-se a isso, o fato de existirem tratamentos diferenciados conforme a forma de uso das drogas, ou seja, também merece atenção a legitimidade ofertada pelas ações das classes sociais mais altas, as quais são capazes de "normalizar" suas condutas e imunizar-se contra a visão de usuário de drogas, tudo isso amparado pela criminalidade dos poderosos, aqui centrada nas indústrias farmacêuticas. A questão que orientará a pesquisa aqui proposta é: quais os mecanismos contemporâneos que garantem a manutenção da seletividade penal na política de drogas? Portanto, o objetivo do presente estudo será o de verificar como ocorre a atual estigmatização existente em relação aos usuários de drogas, bem como os efeitos dessa exclusão. O marco teórico é a criminologia crítica, para estabelecer uma análise crítica sobre a temática.

Para isto, o método de abordagem que servirá de referência para análise das ideias, informações e resultados desta pesquisa é o método dedutivo que parte de observações gerais amparados em uma hipótese para chegar a um objetivo de pesquisa específico. Quanto ao método de procedimento este será o monográfico, de modo que serão usadas várias fontes para que haja embasamento para o tema defendido no trabalho, ofertando a análise de um elemento pontual, distinguindo-se 
de estudos meramente descritivos ou dogmáticos. Sendo que a técnica de pesquisa consistirá na investigação de documentação indireta através de pesquisa bibliográfica com exame de fontes normativas, doutrinárias e pesquisas empíricas de maneira a examinar as informações já demonstradas em outros documentos e aprofundar a referida discussão.

\section{O USUÁRIO DE DROGAS COMO PÁRIA SOCIAL: APRECIAÇÕES CRIMINOLÓ- GICAS DA SELETIVIDADE E DISCRIMINAÇÃO SOCIAL CONTEMPORÂNEA}

O Brasil tem trilhado por um longo caminho na direção da modificação da atual política de drogas, mas o sistema punitivo do país, aliado à política criminal, possui uma grande inclinação em exercer um direito penal máximo à criminalização. Dessa forma, evidenciando "o problema de traçar evoluções históricas de temas político-criminais é definitivamente mais complexo"04, tornando difícil o consenso entre a penalização e a regulamentação do uso, ademais, ainda não existe um amadurecimento acadêmico e jurídico sobre o tema.

Historicamente a política de drogas no Brasil sempre foi de caráter repressivo, inflexível e recheada de violências arbitrárias desde a promulgação da Lei $\mathrm{n}^{\mathrm{o}}$ 6.368/76, até a sua revogação pela Lei $n^{0} 11.343$, de 2006: "[...] a história das penas é seguramente mais horrenda e infame para humanidade que a própria história dos delitos: porque é mais cruel, e talvez mais numerosa, que as violências produzidas pelos delitos" ${ }^{\prime 5}$.

Tal dogmática de drogas traz em seu rol intervenções punitivas que perpetuadamente recaem sobre os grupos mais vulneráveis e marginalizados da sociedade brasileira. A noção do desvio não está na qualidade do ato e sim na consequência da aplicação da regra jurídica (reação social), a qual convalida o papel do desviante, devidamente rotulado ${ }^{06}$. Ademais, cabe enfatizar também que a caracterização como ato desviante depende do ator que a comete, ou seja, alguns sujeitos estão mais a mercê do sistema de repressão às drogas do que outros ${ }^{07}$.

Dessa forma, quando se trata dos alvos preferenciais do sistema penal em

${ }^{04}$ CARVALHO, Salo de. A política criminal de drogas no Brasil (estudo criminológico e dogmático da Lei 11.343/06). $7^{\mathrm{a}}$ ed. São Paulo: Saraiva, 2014. p. 57.

${ }^{05}$ FERRAJOLI, Luigi. Direito e Razão: teoria do garantimo penal. 3. ed. São Paulo: Revista dos Tribunais, 2002. p. 382 .

${ }^{06}$ BECKER, Howard Saul. Outsiders: estudo de sociologia do desvio. Rio de Janeiro: Zahar, 2008. p. 21-22.

${ }^{07}$ BECKER, Howard Saul. Outsiders: estudo de sociologia do desvio. Rio de Janeiro: Zahar, 2008. p. 24. 
matéria de drogas, torna-se imprescindível a análise criminológica da categoria racial, pois “[...] o racismo foi o amparo ideológico em que o país se apoiou e se apoia para se fazer viável. Viável, obviamente, nos termos de um pacto social racialmente fundamentado, do qual as elites nunca abriram mão"08.

O racismo como fator estruturante do sistema penal teve início nos primórdios da colonização do país, o discurso que legitimou o início do racismo estrutural tinha como justificativa o "[...] benefício do colonizado, que lhe impõe seu idioma, sua religião, seus valores, que destrói todas as relações comunitárias que lhe pareça, disfuncionais, que considera seus habitantes como sub-humanos necessitados de tutela" ${ }^{\circ}$. Historicamente no Brasil, negros e negras foram definidos como selvagens, fujões, preguiçosos e desobedientes à raça predisposta a cometer ilícitos ${ }^{10}$. Essa nova espécie não branca e não europeia precisava ser observada:

A construção do criminoso 'tipo criminal' somente foi possível com a exposição absoluta dos encarcerados ao 'olhar dos especialistas', ou seja, a partir de uma relação concreta de poder que se estabelecia prisões, transformando em jaulas destinadas à observação de novas espécies ${ }^{11}$.

A partir da construção desse paradigma racial, se estabeleceram relações de poderes políticos sociais e econômicos ${ }^{12}$. O Brasil foi o último país a abolir o regime escravagista, após uma forte pressão de países do Norte global, porém a sociedade escravocrata do país precisava manter a mão de obra barata ${ }^{13}$. Após a abolição da escravidão, a população negra sem nenhum tipo de auxílio do governo não tinha para onde ir, nem como se manter ${ }^{14}$. Uma parte dos indivíduos foi forçada a permanecer nas fazendas, os demais iniciaram o processo de favelização de lugares ignorados

${ }^{08}$ FLAUZINA, Ana Luiza Pinheiro. Corpo negro caído no chão: o sistema penal e o projeto genocida do estado brasileiro. Brasília, 2006. Dissertação de mestrado, Universidade de Brasília, 2006. p. 13.

09 ZAFFARONI, Eugenio Raúl. Em busca das penas perdidas: a perda de legitimidade do sistema penal. Rio de Janeiro: Revan, 1991. p. 75.

${ }^{10}$ PIRES, Thula. Criminalização do Racismo: entre política de reconhecimento e meio de legitimação do controle social sobre os negros. Brasília: Brado Negro, 2016. p. 47.

${ }^{11}$ CARVALHO, Salo de; DUARTE, Evandro Piza. Criminologia do preconceito: racismo e homofobia nas Ciências Criminais. São Paulo: Saraiva, 2017. p. 50.

${ }^{12}$ BANTON, Michael. A ideia de raça. São Paulo: Martins Fontes, 1991.

${ }^{13}$ GÓES, Luciano. Racismo, genocídio e cifra negra: raízes de uma criminologia antropofágica. In: ANDRADE, Vera Regina Pereira de; CARVALHO, Gisele Mendes de; ÁVILA, Gustavo Noronha de. (Org.). Criminologias e Política Criminal. Florianópolis: COMPEDI, 2014. p. 3.

${ }^{14}$ ARAÚJO, Carlos Eduardo Moreira de; SORARES, Carlos Eugenio Libano; GOMES, Flavio dos Santos; FARIAS, Juliana Barreto. Cidades negras: africanos, crioulos e espaços urbanos no Brasil escravista do século XIX. 2. ed. São Paulo: Alameda, 2006. p. 84. 
pela população "branca e civilizada"15. A questão histórica é primordial para explicar a hipossuficiência da população negra até os dias de hoje, bem como esclarece as relações de poder e os papéis que brancos e não brancos ocupam na sociedade ${ }^{16}$.

A seletividade começa a partir da "punição de pessoas não-convencionais legitimando ainda mais a existência de indivíduos preconcebidos como criminosos. Além da sua posição social desvantajosa, por possuírem educação precária, acabam por realizar obras toscas"17. É exatamente nesse ponto em que a questão racial cruza com o fator estrutural do sistema penal e de hierarquização racial no país, de acordo com o relatório de levantamento de informações penitenciárias realizado em 2016, $53 \%$ da população brasileira se declara negra, e $64 \%$ dos presos no sistema penitenciário nacional são negros ${ }^{18}$.

O racismo juntamente a outras técnicas ditas como científicas (inclusive da própria Criminologia) tratou de institucionalizar a persecução especial contra pessoas não brancas, e ao mesmo tempo proclama até hoje a dita democracia racial no país, a fim de com isso invisibilizar o debate sobre as discriminações operadas (negação). Com isso, propala subcategorias de mestiçagem como a naturalização ou fenômeno social autônomo dos problemas enfrentados e agravados pela atuação coercitiva do Estado ${ }^{19}$.

Essa postura estatal se dá no uso do poder punitivo, o qual é exercido através de um conjunto de órgãos que seleciona os indivíduos que serão punidos, sendo que tal prática é dividida em (ao menos) duas etapas, primária e secundária ${ }^{20}$ (embora não se negue a valia da noção de criminalização terciária).

A etapa primária é aquela que ocorre por meio da lei penal, aqui em específico a legislação de drogas, é a elaboração do tipo penal com conduta proibida voltada para os membros da sociedade como, por exemplo, os crimes do artigo $28 \mathrm{da}$ Lei 11.343/06, adquirir, portar, ter em depósito e transportar drogas sem autorização

\footnotetext{
${ }_{15}$ BATISTA, Vera Malaguti. O Medo na cidade do Rio de Janeiro: dois tempos de uma história. 2. ed. Rio de Janeiro: Revan, 2003. p. 78.

${ }^{16}$ FLAUZINA, Ana Luiza Pinheiro. Corpo negro caído no chão: o sistema penal e o projeto genocida do estado brasileiro. Brasília, 2006. Dissertação (Mestrado) - Universidade de Brasília, 2006. p. 38.

${ }^{17}$ CANTERJI, Rafael Braude. Política criminal e direitos humanos. Porto Alegre: Livraria do Advogado, 2008. p. 100.

${ }^{18}$ INFOPEN. Levantamento Nacional de Informações penitenciárias. Disponível em: < http://depen.gov.br/ DEPEN/depen/sisdepen/infopen/relatorio_2016_22-11.pdf > . Acesso em: 20 abr. 2018.

${ }^{19}$ CARVALHO, Salo de; DUARTE, Evandro Piza. Criminologia do preconceito: racismo e homofobia nas Ciências Criminais. São Paulo: Saraiva, 2017. p. 74-75.

${ }^{20}$ MAÍLLO, Alfonso Serrano. Introducción a la criminología. 6. ed. Madrid: Dynkinson, 2009. p. 439-440.
} 
legal ${ }^{21}$. O poder punitivo exercido na etapa secundária integra o trabalho dos agentes do Ministério Público, advogados, Poder Judiciário e polícia, esses integrantes são responsáveis pela aplicação e efetivação da primeira etapa.

Ocorre que diferente da primeira etapa que seria voltada a sujeitos indeterminados, ao menos esse é o discurso legislativo falsamente prolatado (funções não declaradas/eficácia invertida ${ }^{22}$, a segunda etapa é apontada para indivíduos específicos (em realidade ambas são direcionadas). Através da prática das ações que se enquadrem nos tipos penais e a seleção realizada pelos agentes, são traçados os perfis de criminoso e vítima: "a lei penal não é igual para todos, ou seja, o status de criminoso é distribuído de modo desigual entre os indivíduos"³. Além disso, "verifica-se que a parte selecionada para integrar o rol de criminosos é composta, invariavelmente, por pessoas que estão ou são vulneráveis" ${ }^{24}$.

Via de regra, os usuários de drogas são indivíduos estereotipados pela sociedade com o estigma de "marginal", este conceito vem da chamada consciência moral coletiva que é "o conjunto das crenças e dos sentimentos comuns à média dos membros de uma mesma sociedade um sistema determinado que tem vida própria; podemos chamá-lo de consciência coletiva ou comum"25. Ocorre que ordinariamente a consciência coletiva está eivada de preconceitos, que têm como base fundamentos sociais e estéticos, tais quais explanados na obra de Lombroso $^{26}$, de maneira que estes preconceitos derivam da constante revitalização criminológico-positivista.

Dessa maneira, quanto mais vulnerável o indivíduo, mais fácil será a aproximação dele da situação criminalizadora. Nos primórdios da civilização a motivação do uso de drogas tinha relação com os cultos religiosos e terapêuticos, na contemporaneidade, com o atual contexto de globalização e as frustrações de uma socieda-

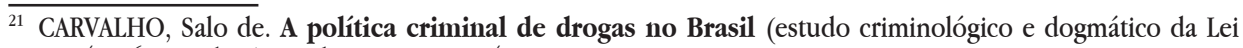
11.343/06). 7. ed. São Paulo: Saraiva, 2014. p. 25.

${ }^{22}$ Os estudos de Andrade explicitam quais seriam as funções declaradas e não declaradas pelo sistema penal. "A eficácia invertida significa, então, que a função latente e real do sistema penal não é combater (reduzir e eliminar) a criminalidade, protegendo bens jurídicos universais e gerando segurança pública e jurídica, mas, ao invés construí-la seletiva e estigmatizantemente, e neste processo reproduzir, material e ideologicamente, as desigualdades e assimetrias sociais (de classe, de gênero, de raça)". ANDRADE, Vera Regina Pereira de. Pelas mãos da criminologia: o controle penal para além da (des)ilusão. Rio de Janeiro: Revan, 2012. p. 136.

${ }^{23}$ BARATTA, Alessandro. Criminologia crítica e crítica do direito penal: introdução à sociologia do direito penal. 3. ed. Rio de Janeiro: Revan/ICC, 2002. p. 162.

${ }^{24}$ CANTERJI, Rafael Braude. Política criminal e direitos humanos. Porto Alegre: Livraria do Advogado, 2008. p. 100 .

25 DURKHEIM, Émile. A divisão do trabalho social. 2. ed. São Paulo: Martins Fontes, 1999. p. 50.

${ }^{26}$ LOMBROSO, Cesare. $\mathbf{O}$ homem delinquente. Porto Alegre: Rivardo Lens, 2001. 
de que vive em busca da felicidade através do consumismo exacerbado os indivíduos acabam "fadados ao sofrimento, à constante restrição da eterna busca pelo princípio do prazer" 27 .

Ademais, deve ser levada em consideração toda a desvantagem de posicionamento social dos indivíduos definidos como usuários de drogas. No Brasil todo empenho governamental, sobretudo policial, está voltado às favelas, como se lá fosse o único lugar onde há drogas ${ }^{28}$, é sabido que os problemas atinentes às drogas são distribuídos igualmente entre os grupos sociais e econômicos, a diferença é que quem detém o poder coercitivo são agentes das classes sociais abastadas, "as classes mais poderosas utilizam esse mecanismo por meio do direito penal e de todo sistema punitivo, para consolidar um sistema de controle e dominação estrutural”29. Esse fato invisibiliza os crimes dos poderosos, que por meio de suas ações ou omissões que causam danos sociais massivos, aqui em específico, em relação ao tráfico de drogas e até mesmo os lobbys com a indústria farmacêutica ${ }^{30}$.

O modelo político capitalista, voltado ao consumismo, é uma das prerrogativas culminantes da sociedade, a maior parte dos indivíduos vive em prol do consumo constante, tornando-se a religião dominante do século XXI ${ }^{31}$. Eleva-se assim o culto ao materialismo e seus objetos de lazer, que conforme Weigert fazem parte do "efeito perverso da moral consumista" 32 . Contudo, mesmo os excluídos do consumismo almejam de alguma forma suprir e encobrir suas frustrações pela busca do materialismo que requer abono financeiro, dessa maneira acabam optando pelo que está ao seu alcance, que na maioria das vezes é o consumo de drogas na busca de novas sensações, a prática de furtos e roubos para que se consiga burlar o sistema e obter os objetos com constantes apelos comerciais.

Por outro lado, deve-se deixar esclarecido que também existem aquelas pes-

\footnotetext{
${ }^{27}$ WEIGERT, Mariana de Assis Brasil e. Uso de Drogas e Sistema Penal: entre o proibicionismo e a redução de danos. Rio de Janeiro: Lumen Juris, 2010. p. 18.

${ }^{28}$ ROSA, Alexandre Morais da; AMARAL, Augusto Jobim do. Cultura da punição: a ostentação do horror. 3. ed. Florianópolis: Empório do Direito, 2017. p. 108-109.

${ }^{29}$ RUBIO, David Sánchez; FRUTOS, Juan Antonio Senent de. Teoria crítica del derecho: nuevos horizontes. Sevilla: Centro de Estudios Jurídicos y Sociales Mispat, A.C., 2013. p. 98.

${ }^{30}$ SARMIENTO, Camilo Ernesto Bernal; CABEZAS, Sebastián; FORERO, Alejandro; RIVERA, Iñaki; VIDAL, Iván. Más allá de la criminología. Un debate epistemológico sobre el daño social, los crímenes internacionales y los delitos de los mercados. In: RIVERA, Iñaki (Coord.). Delitos de los Estados, de los Mercados y daño social: debates en criminología crítica y sociología jurídico-penal. Barcelona: Anthropos, 2014. p. 54-55.

${ }^{31}$ LATOUCHE, Serge. O desafio do decrescimento. Tradução de António Viegas. Lisboa: Instituto Piaget, 2012. p. 42 .

${ }^{32}$ WEIGERT, Mariana de Assis Brasil e. Uso de Drogas e Sistema Penal: entre o proibicionismo e a redução de danos. Rio de Janeiro: Lumen Juris, 2010. p. 20.
} 
soas que possuem poder aquisitivo, e que estão em um patamar social mais elevado e que mesmo assim fazem o uso de drogas. As motivações para o uso são igualmente variadas, seja por motivos emocionais de falta de afeto como forma de chamar atenção dos pais, seja por terem que reprimir seus instintos e suas emoções em razão da sociedade e instituições morais e religiosas ${ }^{33}$. Em realidade a pluralidade de usuários é ocultada na dinâmica de funcionamento do sistema penal, já que sua atuação seletiva e elitista impede a observação ampla do tema das drogas e seus usuários, tampouco permite a leitura sobre os danos sociais gerados pela postura punitiva sobre essas pessoas ${ }^{34}$.

Também fazendo uma análise sob a ótica da psicanálise freudiana, estabelece-se que o uso de drogas é motivado pela busca da satisfação do prazer $^{35}$, por curiosidade porque os amigos também usam, fragilidade física, moral, psíquica, cultural, política e social, "o uso de drogas ilícitas compõe, junto com outros elementos da cultura, o quadro de manifestações estéticas das políticas de ruptura" ${ }^{36}$. Enfim, diversas são as motivações as quais têm origem a partir das decepções, demandas inatingíveis, habituais sofrimentos. Sendo assim, há opção em satisfazer o ego dolorido com uso de substâncias que iludem o psíquico, mesmo que brevemente.

Isto posto, observa-se a deslegitimação do sistema penal por meio do paradigma repressivo e do consenso moral existente em relação à política de drogas no Brasil, uma vez que a rotulação e estigmatização dos indivíduos acaba desarticulando todo o discurso jurídico (especialmente constitucional) de igualdade dos indivíduos perante a lei. Dessa forma, "por conta da repressão e do estigma, a situação psíquica dos dependentes de droga criminalizados se transforma não poucas vezes no sentido do estereótipo hoje dominante" ${ }^{37}$. Esse processo gera consequentemente ainda mais desigualdades e isolamento social, mesmo que o uso de drogas atinja todas as classes sociais.

Nesse sentido, ainda depara-se com a repressão de grupos sociais especí-

\footnotetext{
33 BECKER, Howard Saul. Outsiders: estudo de sociologia do desvio. Rio de Janeiro: Zahar, 2008. p. 38.

${ }^{34}$ BARATTA, Alessandro. Introducción a una sociología de la droga: problemas y contradicciones del controle penal de las drogodependencias. 1993. Disponível em: < http://www.alfonsozambrano.com/doctrina_penal/introduccion_sociologia_drogas.pdf. $>$. Acesso em: 07 mar. 2018.

35 FREUD, Sigmund. O mal-estar na civilização. Rio de Janeiro: Imago, 1997. p. 52.

${ }^{36}$ CARVALHO, Salo de. A política criminal de drogas no Brasil (estudo criminológico e dogmático da Lei 11.343/06). 7. ed. São Paulo: Saraiva, 2014. p. 62.

${ }^{37}$ BARATTA, Alessandro. Introducción a una sociología de la droga: problemas y contradicciones del controle penal de las drogodependencias. 1993. Disponível em: < http://www.alfonsozambrano.com/doctrina_penal/introduccion_sociologia_drogas.pdf. > . Acesso em: 07 mar. 2018. p. 207. Tradução nossa.
} 
ficos com práticas de "(re)afirmação de estereótipos e de distribuição arbitrária e seletiva de etiquetas ocorre o incremento e a densificação, na estrutura dos aparatos da seguridade pública, da lógica militarizada"38. Portanto, debater as questões relativas aos usuários de drogas sem ampliar o contexto jurídico-político contemporâneo é permanecer sobre a égide da ignorância fenomenológica e que se pretende aqui desvelar.

\section{DROGAS E SUA INTERVENÇÃO CONTEMPORÂNEA NO BRASIL: A RUPTURA EPISTEMOLÓGICA COMO FORMA DE OBSERVAÇÃO DOS DANOS SOCIAIS}

Atualmente a intervenção sobre o tema das drogas no Brasil é orientada por uma política proibicionista dentro de uma base jurídico-dogmática igualmente restritiva, mas aplicada de forma flexível quando conveniente. Esse sistema é criticado por grande parte da doutrina, pois "os defensores da legalização sustentam que esta seria a medida mais eficiente na atualidade para quebrar a espinha dorsal do crime organizado em todo o mundo" 39 .

A política de drogas permanece com o impasse da lógica discursiva de legislações e políticas do século passado, que contrariando a crítica e o estudo criminológico em relação ao fracasso da política de guerra às drogas, seguiu aumentando as restrições penalizadoras. Nesse sentido, pode-se asseverar que a intenção estatal é propalar a extinção das drogas do seio social por meio de ações repressoras, ao mesmo tempo em que nega o flagrante fracasso obtido com tal postura, "mesmo assim, seus seguidores não se cansam de propor doses mais fortes do mesmo remédio" ${ }^{\text {" }}$.

Visualiza-se que a elaboração da atual política criminal de drogas no Brasil (criminalização primária), por meio dos seus legisladores tem "visado apresentar respostas rápidas à mídia e à coletividade, apresenta, com frequência, medidas com-

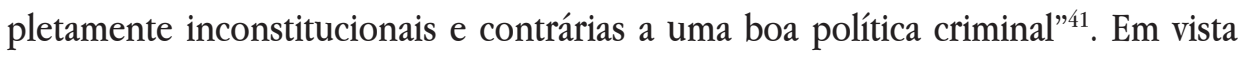
disto, o processo de criminalização tem focado em cuidar dos interesses das classes

38 CARVALHO, Salo de. A política criminal de drogas no Brasil (estudo criminológico e dogmático da Lei 11.343/06). $7^{\mathrm{a}}$ ed. São Paulo: Saraiva, 2014. p. 76.

39 ROBINSON, Rowan. O grande livro da cannabis: guia completo de seu uso industrial, medicinal e ambiental. Rio de janeiro: Zahar, 1999. p. 108.

${ }^{40}$ ROLIM, Marcos. A síndrome da rainha vermelha: policiamento e segurança pública no século XXI. 2. ed. Rio de Janeiro: Jorge Zahar, 2009. p. 174.

${ }^{41}$ CASTRO, Fernando Borba de. Justiça Restaurativa: um olhar para além da repressão. Florianópolis: Empório do Direito, 2015. p. 24. 
dominantes e de interesses mercadológicos, seja com articulações de ocultação seja com a legitimação dos atos realizados por seus agentes.

Seguindo as bases anteriormente estipuladas os usuários de drogas assim como outros sujeitos pertencentes às classes sociais mais baixas passam a ser alvo do sistema penal, enquanto os meios de comunicação de massa tratam de reforçar os estereótipos de catalogação desses desviantes: "combinam com a imagem que corresponde à descrição fabricada, deixando de fora outros tipos de delinquentes (delinquência de colarinho branco, dourada, de trânsito, etc.)"²².

Nesse sentido, o relatório global de políticas de drogas divulgado pela $\mathrm{ONU}$ em 2011 explanou que "a guerra global contra as drogas fracassou, deixando em seu rastro consequências devastadoras para pessoas e sociedades em todo o mundo” ${ }^{” 3}$. Demonstrando assim que a atual intervenção de políticas antidrogas, recursos de erradicação de produção, repressões e criminalização dos usuários não foram capazes de diminuir a disponibilização nem o consumo de drogas a nível mundial, tampouco auferem os efeitos positivos que prometem.

Demonstra-se com isso que a utilização sucessiva somente de métodos punitivos é ineficaz; além disso, os recursos públicos poderiam ser melhores empregados em novos métodos terapêuticos, uma vez que um dos ditos objetivos da atual legislação é prezar pela saúde pública e individual dos usuários e dependentes ${ }^{44}$. Nesse direcionamento ao postar a saúde dos usuários como real preocupação a postura punitiva seria a prioridade a ser extirpada, bem como a mudança completa nas intervenções políticas. Por conseguinte, "economicamente, percebemos que a 'guerra às drogas' tem função de ocultação dos desequilíbrios e conflitos entre classes, determinando legitimidade para imposição de legislações seletivas, que originam violência institucional" ${ }^{25}$.

Em suma, o modelo brasileiro de repressão às drogas leva ao enrijecimento de legislações penais, com justificativas criadas a partir do controle social informal que elabora emergências de criminalização estereotipadas pela mídia tendo como

\footnotetext{
$\overline{42}$ ZAFFARONI, Eugenio Raúl. Em busca das penas perdidas: a perda de legitimidade do sistema penal. Rio de Janeiro: Revan, 1991. p. 130.

${ }^{43}$ ONU, Relatório da comissão global de políticas de drogas 2011. Disponível em: < http://www.globalcommissionondrugs.org/wpcontent/themes/gcdp_v1/pdf/Global_Commission_Report_Portuguese.pdf $>$. Acesso em: 25 fev. 2016.

${ }^{44}$ CASTRO, Fernando Borba de. Justiça Restaurativa: um olhar para além da repressão. Florianópolis: Empório do Direito, 2015. p. 11.

${ }^{45}$ CARVAlHO, Salo de. A política criminal de drogas no Brasil (estudo criminológico e dogmático da Lei 11.343/06). 7. ed. São Paulo: Saraiva, 2014. p. 179.
} 
fito a seletividade de inimigos ${ }^{46}$. Não obstante, observa-se que uma das finalidades da doutrina proibicionista é de controle sanitário, influência no comércio de produção e venda de drogas lícitas e ilícitas com destaque para o poder das indústrias farmacêuticas, envolvendo outros interesses políticos do Estado de caráter capitalista. Seguindo esta lógica, em relação ao Estado capitalista, "a 'sociedade de consumo' repousa sob um ideal, mas ignora que este ideal é o toxicômano que o realiza. Com efeito, o sonho de todo publicitário, de todo fabricante é de realizar o objeto do qual ninguém poderia mais passar sem" ${ }^{7}$.

Entretanto, apesar do quadro de ineficácia e caos gerado pela atuação do sistema penal em relação às drogas e da cegueira social para seus processos de dependência, sem adentrar nas explorações do mercado em relação ao assunto, se poderia questionar os motivos para manutenção dessa forma de intervenção. Alude-se isso em tom de ironia, haja vista que diante desse fracasso declarado e da orientação em prol da saúde dos usuários já deveriam haver mudanças significativas na relação com as drogas (tanto em matéria legal quanto de políticas públicas), mas conforme já afirmado anteriormente as atividades ilícitas fazem parte da dinâmica de funcionamento do capitalismo ${ }^{48}$.

Ademais, cabe dizer que a simples modificação de tratamento das drogas não transforma a questão em algo simples, ou seja, por mais que se defenda aqui a alteração no posicionamento estatal da óptica punitiva para de saúde, por exemplo, não significa que a complexidade seria reduzida ${ }^{49}$.

Em toda a sua complexidade, o uso abusivo de drogas na nossa sociedade, não pode ser visto a partir de um único prisma. Há diversas questões interligando diferentes sujeitos, constituindo uma rede de significações que não resiste às nossas costumeiras simplificações. Às nossas "valas comuns" conceituais ${ }^{50}$.

Dito isso, a fim de evitar qualquer perda na observação da complexidade do assunto em pauta, indaga-se acerca dos objetos criminológicos, que apesar de ainda

\footnotetext{
$\overline{46}$ ZAFFARONI, Eugenio Raúl. A palavra dos mortos: conferências de criminologia cautelar. São Paulo: Saraiva, 2012. p. 309.

${ }^{47}$ MELMAN, Charles. Alcoolismo, delinquência, toxicomania: uma outra forma de gozar. São Paulo: Escuta, 2002. p. 94.

${ }^{48}$ HARVEY, David. 17 contradições e o fim do capitalismo. São Paulo: Boitempo, 2016. p. 59-60.

${ }^{49}$ ROSA, Pablo Ornelas. Drogas. In: CARLEN, Pat; FRANÇA, Leandro Ayres (Org.). Criminologias alternativas. Porto Alegre: Ciências Criminais, 2017. p. 267.

${ }^{50}$ CRUZ, Walter Firmo de Oliveira. Intoxicação e exclusão social. Revista da Associação Psicanalítica de Porto Alegre. Porto Alegre, $n^{\circ} 24,2003$. p. 29.
} 
adaptados, tendo em vista a realidade criminalizada das drogas, parecem dar mostras de sua insuficiência. Portanto, a fim de dar nova roupagem aos estudos do tema, bem como ampliar a gama dos efeitos apreciados, há necessidade de recepcionar a ruptura epistemológica trazida pela ideia dos danos sociais. Justifica-se a inserção disso em razão de que os efeitos produzidos pela postura punitiva do sistema penal na relação com as drogas vão muito além dos processos de criminalização, gerando diversas reações a partir do seu posicionamento restritivo e seletivo sobre a sociedade brasileira.

Assim a concepção do dano social (compreendido enquanto processos que minam a vida humana e não-humana $)^{51}$ como objeto criminológico apresenta uma série de vulnerabilizações causadas e que não se encontram ligadas às ideias de crime ou desvio. Atende-se com isso um anseio da própria criminologia crítica, para desvelar ações lesivas e danosas contra grupos ou pessoas, mas que não estavam abrangidos pelas noções do desvio ou do crime ${ }^{52}$.

Igualmente a ruptura proposta permite apreciar as ações relacionadas às drogas sob um novo prisma, ou seja, os crimes do Estado e do Mercado. Essa afirmativa retoma a crítica da passividade estatal em modificar sua postura em relação ao tema das drogas, pois ao ter conhecimento da ineficácia das suas ações e ainda decidir pela manutenção, há evidentemente a produção de danos sociais em virtude de sua omissão deliberada $a^{53}$.

O papel de grandes corporações é evidente no processo de produção de danos sociais, haja vista seu caráter internacional, pois suas incorporações e operacionalização não ficam restritos a nenhum Estado ou região. Ademais o poder econômico desses agentes proporciona igualmente um poder político capaz de influenciar campanhas e auxiliar efetivamente em suas demandas, conforme expõe Budó ${ }^{54}$ acerca do domínio de poucas corporações sobre a produção de grãos, frutas, "até fertilizantes químicos em geral e a produção de transgênicos". Por esses motivos não

\footnotetext{
${ }^{51}$ LASSLETT, Kristian. Crime or social harm? A dialectical perspective. Crime, Law and Social Change. v. 54, n. 1, p. 1-19, 2010. p. 12.

52 SARMIENTO, Camilo Ernesto Bernal; CABEZAS, Sebastián; FORERO, Alejandro; RIVERA, Iñaki; VIDAL, Iván. Más allá de la criminología. Un debate epistemológico sobre el daño social, los crímenes internacionales y los delitos de los mercados. In: RIVERA, Iñaki (Coord.). Delitos de los Estados, de los Mercados y daño social: debates en criminología crítica y sociología jurídico-penal. Barcelona: Anthropos, 2014. p. 48.

53 SARMIENTO, Camilo Ernesto Bernal; CABEZAS, Sebastián; FORERO, Alejandro; RIVERA, Iñaki; VIDAL, Iván. Más allá de la criminología. Un debate epistemológico sobre el daño social, los crímenes internacionales y los delitos de los mercados. In: RIVERA, Iñaki (Coord.). Delitos de los Estados, de los Mercados y daño social: debates en criminología crítica y sociología jurídico-penal. Barcelona: Anthropos, 2014. p. 65.

${ }^{54}$ BUDÓ, Marília De Nardin. Danos silenciados: a banalidade do mal no discurso científico sobre o amianto. Revista Brasileira de Direito. v. 12, n. 1, p. 127-140, jan./jun. 2016. p. 119.
} 
há razão para imaginar que na relação com as drogas (algo diretamente conectado às indústrias farmacêuticas, por exemplo) o comportamento de agentes estatais ou particulares seria diferente, ou não produziria danos sociais massivos.

A superação do objeto criminológico por meio do dano social visa exatamente afastar as violações (ambientais, sociais, etc.) desse espectro jurídico limitado, de maneira a denunciar os prejuízos às vítimas, sem, contudo, carecer sempre do aval da legislação. Não obstante, apresentam-se neste contexto complexo respostas dinâmicas de rearticulação constante, e igualmente de reflexão ampla do próprio sistema capitalista em sua atuação pragmática de transformação/destruição, juntamente aos processos de ocultação dos grandes danos produzidos por Estados e Mercados $^{55}$.

Portanto, ao recepcionar os danos sociais enquanto objeto de estudo criminológico busca-se impedir as renovações de ocultação ou legitimação de atividades de classe por parte do Estado em relação às drogas, ao mesmo tempo em que se denuncia que além dos efeitos da criminalização sobre sujeitos selecionados, ainda restam outros danos produzidos pela postura punitiva sobre grupos vulneráveis da população. Em adendo se infere que tal proposição antecipa-se a modificação na forma de tratamento, conforme já aludido, visto que mesmo que fosse dado um enfoque direcionado à saúde dos usuários, isso não seria um impedimento ao ter como base os danos sociais.

Diante disso, torna-se viável observar os comportamentos mercadológicos e estatais em relação às drogas, mas que têm como base a sua legitimação para determinadas classes sociais. Tal enfoque se justifica para evidenciação dos tratamentos seletivos do sistema penal, bem como revela a forma de comportamento de grandes agentes públicos ou privados na invisibilização de suas atividades e na proteção de seus interesses.

\section{4 "DOENÇAS" DE CASTAS E AS CORPORAÇÕES DE DROGAS: O TRATAMENTO DIFERENCIADO NA SOCIEDADE CAPITALISTA DE CLASSES}

A pauta punitiva sobre as drogas tem um novo capítulo quando passa a se

${ }_{55}$ NATALI, Lorenzo. Green criminology, victimización medioambiental y social harm. El caso de Huelva (España). Revista Crítica Penal y Poder, nº 7, p. 5-34, septiembre. 2014. p. 23. 
observar o comportamento do sistema penal diante dos danos sociais e das grandes corporações. Afirma-se isso pela análise da forma de tratamento entre sujeitos considerados desviantes pelo uso de drogas (ilícitas) e aqueles que se submetem a algum tratamento com medicamentos (drogas lícitas), sendo que muitos desses supostos remédios possuem fórmulas ou componentes semelhantes (e por vezes idênticas) às drogas comercializadas ilegalmente ${ }^{56}$.

Conforme já aludido anteriormente o sistema penal emprega diversas ferramentas contra o uso de drogas ilícitas, mas para o seu sucesso a variação das estratégias e as deduções negativas rotuladas aos sujeitos abarcados pelas normas devem ser automáticas, o que não ocorre com indivíduos medicados. Demonstra isso Becker ao mencionar o modo de tratar pessoas que fazem uso de maconha nos Estados Unidos:

[...] O ato é ilegal e passível de punições severas. Sua ilegalidade torna o acesso à droga difícil, erguendo obstáculos imediatos diante de qualquer um que deseje usá-la. O uso efetivo pode ser perigoso, pois prisão e encarceramento são sempre consequências possíveis. Além disso, caso a família, os amigos ou o patrão de um usuário descubram que ele utiliza maconha, eles podem lhe atribuir as características acessórias que de hábito o fumante é irresponsável e incapaz de controlar o próprio comportamento, que talvez até seja louco, podem puni-lo com vários tipos de sanções informais, mas extremamente eficazes como o ostracismo ou a retirada de afeto. Finalmente, desenvolveu-se um conjunto de idéias (sic) tradicionais definindo a prática como uma violação de imperativos morais, como um ato que leva a perda do autocontrole, à paralisia da vontade e, por fim, à escravidão à droga ${ }^{57}$.

A aparente desconexão com o quadro legal nacional é facilmente refutada, embora o usuário não seja punido com a penalidade prisional, existem similitudes e flexibilidades legais que permitem a autuação desses sujeitos como traficantes em diversas situações. Soma-se a isso ainda os fatores da seletividade (incluindo-se a formação de autoimagem negativa $)^{58}$ que explica tanto a persecução de sujeitos determinados, quanto a ocultação de atos desviantes de agentes que pertencem às

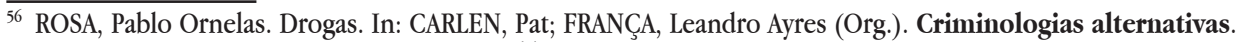
Porto Alegre: Ciências Criminais, 2017. p. 264.

${ }^{57}$ BECKER, Howard Saul. Outsiders: estudo de sociologia do desvio. Rio de Janeiro: Zahar, 2008. p. 70.

${ }^{58}$ BECKER, Howard Saul. Outsiders: estudo de sociologia do desvio. Rio de Janeiro: Zahar, 2008. p. 41-42.
} 
classes sociais mais altas.

Destarte, não é suficiente o impedimento da atuação penal sobre pessoas de classes médias e altas no consumo de drogas, até mesmo porque a seletividade do sistema não se restringe a atribuições do desviante, ou seja, os demais status também são determinados de forma direcionada (quem pode ser vítima) ${ }^{59}$. Porém, o ponto culminante se dá na legitimação (por meios legais-jurídicos) de comportamentos desviantes que envolvam drogas, através de práticas capitalistas.

No caso das drogas a adaptação do mercado e do capitalismo se dá para blindar determinadas classes sociais de toda e qualquer atuação do sistema penal. Esse fenômeno aponta para indústrias farmacêuticas, mas se aprofunda por fatores sociais, como a relação com médicos e outros mecanismos de facilitação.

Cabe dizer que os produtores de fármacos já eram alvo de observação criminológica, ao menos quando se tem como prisma a ideia dos danos sociais ${ }^{60}$. Essa atenção é explicada porque sua atuação não necessita ser direta para produzir essa espécie de danos em grandes proporções, pois mesmo de forma indireta (ao não fornecer medicamentos ou dificultar o seu acesso) às corporações de drogas lícitas acarretam inúmeros prejuízos e mortes globalmente ${ }^{61}$.

Portanto, as ações realizadas por essa parcela do mercado não são apenas ocultadas, mas sim acabam por ser facilitadas pelo Estado, congregando juntos em uma amálgama de crimes dos poderosos (crimes of the powerful), sem qualquer vislumbre de impedimento, haja vista que não se pode esperar a coerção penal de um dos sujeitos que participa da relação ${ }^{62}$. É salutar mencionar que esse comportamento combinado entre interesses estatais e de ordem capitalista são constantes historicamente (crimes dos poderosos), conforme se verifica nas apreciações de Sutherland ${ }^{63}$ e mais contemporaneamente de Barak $^{64}$.

A situação revela que as condutas do Estado em relação às indústrias farmacêuticas estão adaptadas à realidade capitalista de conivência e permissividade

${ }^{99}$ ANDRADE, Vera Regina Pereira de. Pelas mãos da criminologia: o controle penal para além da (des)ilusão. Rio de Janeiro: Revan, 2012. p. 138-139.

${ }^{60}$ ROSA, Pablo Ornelas. Drogas. In: CARLEN, Pat; FRANÇA, Leandro Ayres (Org.). Criminologias alternativas. Porto Alegre: Ciências Criminais, 2017. p. 267.

${ }^{61}$ LASSLETT, Kristian. Crime or social harm? A dialectical perspective. Crime, Law and Social Change, v. 54, n. 1, p. 1-19, 2010. p. 12.

${ }^{62}$ TOMBS, Steve; WHYTE, David. La empresa criminal: por qué las corporaciones deben ser abolidas. Barcelona: Icaria, 2016. p. 76-78.

${ }^{63}$ SUTHERLAND, Edwin H. White-collar criminality. American Sociological of Law, v. 5, n. 1, p. 1-12, feb., 1940. p. 2.

${ }^{64}$ BARAK, Greg. The crimes of the powerful and the globalization of crime. Revista Brasileira de Direito, v. 11, n. 2, p. 104-114, jul./dez. 2015. p. 105-106. 
de determinadas classes sociais, operando assim um mecanismo de reforço econômico na proteção dos sujeitos que realizem tais condutas, ao mesmo tempo em que tratam de legitimar suas ações com instrumentos jurídicos, algo completamente inviabilizado para sujeitos que se encontrem mais abaixo na pirâmide social. Nesse sentido, quanto maior for a cumplicidade entre Estados e Mercados, mais fácil será de o poder estatal servir às vontades e interesses econômicos das grandes corporações "estranhas" ao Estado ${ }^{65}$.

Essa articulação deve ser entendida de forma ampla, a fim de evitar a singularização de indivíduos isolados como responsáveis por práticas corporativas mundialmente difundidas, sendo que tal fato já foi corroborado por estudos na indústria farmacêutica (utilizando desde pessoas que estavam em comando nas empresas até estudantes, e obtendo respostas similares nas projeções de danos sociais). Em igual sentido, está o quadro histórico das corporações farmacêuticas, as quais constituíram-se entre as mais incidentes em situações de suborno, corrupção, negligência criminosa e produção de drogas inseguras ${ }^{66}$.

Em adendo infere-se ainda que a realização de condutas lesivas por parte de corporações farmacêuticas, contra a população em geral, apresenta por parte de seus gestores "justificativas". Logo, segundo os estudos na área os desviantes corporativos da área farmacológica apresentam suas próprias técnicas de neutralização, que vão desde "o governo exagera o perigo para os consumidores da maioria dos produtos" até "o lucro é enfatizado acima de tudo no meu local de trabalho"67.

Apesar das ressalvas e técnicas apresentadas, a produção de medicamentos por parte dessas empresas é usual ao funcionamento do Mercado, porém o que se destaca aqui é a adoção das vias legitimadas para regularizar o consumo de drogas por parte de determinados indivíduos ${ }^{68}$. Revela-se assim a faceta mais recente do desvio corporativo, pois ao delimitar que sua atuação se dá sobre pessoas doentes, circunscrevendo sua esfera na área da saúde, resta apartado todo e qualquer sujeito definido como usuário de drogas, o que repete o raciocínio divisório entre "nós" e

65 TOMBS, Steve; WHYTE, David. La empresa criminal: por qué las corporaciones deben ser abolidas. Barcelona: Icaria, 2016. p. 77.

${ }^{66}$ BRAITHWAITE, John. Corporate crime in pharmaceutical industry. New York: Routledge, 2013. p. 2-6.

${ }^{67}$ PIQUERO, Nicole Leeper; TIBBETTS, Stephen G.; BLANKENSHIP, Michael B. Examining the role of differential association and techniques of neutralization in explaining corporate crime. Deviant Behavior, n. 26, $\mathrm{p}$. 159-188, 2005. p. 170-171.

${ }^{68}$ ROSA, Pablo Ornelas. Drogas. In: CARLEN, Pat; FRANÇA, Leandro Ayres (Org.). Criminologias alternativas. Porto Alegre: Ciências Criminais, 2017. p. 267. 
"eles"69.

Os estudos nesse campo se intensificaram nas últimas décadas em razão do próprio incremento do consumo, tendo como referencial inicial a incidência de medicamentos/drogas durante a infância e juventude, motivando diversas pesquisas na seara escolar e universitária ${ }^{70}$.

Contudo, a atenção se amplia à medida que se observa a expansão no uso de medicamentos/drogas a nível global, até mesmo porque essas mesmas substâncias estão definidas a serem utilizadas de modo restritivo, sendo que somente receitas médicas autorizariam o seu consumo. Apregoa-se assim um segundo nível na proteção dos usuários de alto escalão, a legitimidade trazida pelas corporações farmacêuticas é asseverada pelas prescrições médicas que os definem como doentes. Tais camadas expõem tanto a produção de drogas, dentro de um mercado lícito e seletivo, quanto a seu resguardo a partir do discurso científico da categoria médica em relação ao tema.

Logo, o crescimento produtivo no consumo de drogas legalizadas é acompanhado pela crescente de receitas/prescrições indevidas, indo desde analgésicos, opioides até estimulantes (adderall/ritalina) ${ }^{71}$. É imprescindível determinar que essas pessoas sejam consideradas doentes, a fim de afastar delas qualquer tratamento punitivo de intervenção penal, o qual é restrito aos usuários de drogas.

Clarifica-se que a justificação dos comportamentos além da esfera corporativa-estatal, na produção e comercialização para a elite, a qual tem acesso direto aos médicos a qualquer tempo, conta ainda com a necessidade de justificar individualmente e socialmente seus comportamentos. Significa dizer que os mecanismos de imunização são diversos, mas alguns se destacam como, por exemplo, o da automedicação, quando estudantes apresentam diagnósticos pessoais, no caso do estudo de déficit de atenção ou hiperatividade, para referendar o consumo de estimulantes (casos de adderall e ritalina), seja do ponto de vista fisiológico ou moral ${ }^{72}$.

É importante salientar que estes remédios são em sua maioria variações de drogas vendidas ilicitamente (ao menos em sua composição) e que seu consumo já

$\overline{69}$ ANDRADE, Vera Regina Pereira de. Pelas mãos da criminologia: o controle penal para além da (des)ilusão. Rio de Janeiro: Revan, 2012. p. 166.

${ }^{70}$ MOHAMED, A. Rafik; FRITSVOLD, Erik D. Dorm Room Dealers: Drugs and the Privileges of Race and Class. Boulder: Lynne Rienner Publishers, 2010.

${ }^{71}$ FISCHER, Benedikt; ARGENTO, Elena. Prescription Opioid Related Misuse, Harms, Diversion and Interventions in Canada: A Review. Pain Physician Journal, n. 15, p. 191-203, 2012. p. 192.

72 DESANTIS, Alan D.; HANE, Audrey Curtis. "Adderall is definitely not a drug": Justifications for the illegal use of ADHD stimulants. Substance use \& misuse, v. 45, n. 1-2, p. 31-46, 2010. p. 40. 
foi verificado como "recreativo" por números significativos de seus usuários.

Adderall (anfetaminas de sais mistos) é o medicamento mais prescrito para crianças e adultos com TDAH, com Ritalina (Metilfenidato) e Dexedrina (dextroanfetamina) sendo também considerada farmacoterapia de primeira linha. Devido ao potencial de abuso e dependência física e psicológica, a Administração de Repressão às Drogas dos EUA (DEA) classifica esses estimulantes como substâncias do Anexo II (Woodworth, 2000). Consequentemente, Adderall, Ritalina e Dexedrine estão legalmente disponíveis apenas por prescrição, com um limite de 30 dias de doses e sem recargas. Além disso, os medicamentos do Anexo II estão sujeitos a cotas de produção estabelecidas pelo DEA.2. Apesar destas restrições do Anexo II, o uso ilegal de estimulantes de TDAH tornou-se cada vez mais popular durante o final dos anos 90 nos campi universitários americanos [...]. Especificamente, Babcock e Byrne descobriram que $16 \%$ dos 283 alunos da amostra utilizavam Ritalina recreativamente. Hall et al. (2005) relataram que 17\% dos 179 homens e $11 \%$ das 202 mulheres entrevistadas usavam drogas estimulantes ilícitas. Esse número foi mais que o dobro em Low e a investigação de Gendaszek de uma pequena faculdade da Nova Inglaterra com 35,5\% dos 150 alunos da amostra relatando o uso ilícito de anfetaminas legais ${ }^{73}$.

A exemplificação supramencionada, assim como outras doenças, não tem um diagnóstico fechado, dependendo de testes para sua determinação. Além da natural flexibilidade e subjetividade no processo de constatação da (dita) doença, conta-se ainda com a pressão econômica de indivíduos pertencentes a determinadas elites sociais, juntamente a um mercado próprio de produção e consumo de drogas, e que aufere legitimidade como forma de impedir a inserção penal e manter os pri-

\footnotetext{
${ }_{73}$ DESANTIS, Alan D.; HANE, Audrey Curtis. "Adderall is definitely not a drug": Justifications for the illegal use of ADHD stimulants. Substance use \& misuse, v. 45, n. 1-2, p. 31-46, 2010. p. 32. Tradução nossa. "Adderall (mixed salts amphetamine) is the most widely prescribed medicine for children and adults with ADHD, with Ritalin (Methylphenidate) and Dexedrine (dextroamphetamine) also being considered first-line pharmacotherapy. Because of the potential for abuse and psychological and physical dependency, the U. S. Drug Enforcement Administration (DEA) classifies these stimulants as Schedule II substances (Woodworth, 2000). Consequently, Adderall, Ritalin, and Dexedrine are legally available only through prescription, with a limit of 30 days' worth of doses, and no refills. Additionally, Schedule II drugs are subject to production quotas set by the DEA.2. Despite these Schedule II restrictions, the illegal use of ADHD stimulants has become increasingly popular during the late 1990s on American college campuses [...]. Specifically, Babcock and Byrne found that $16 \%$ of the 283 students sampled used Ritalin recreationally. Hall et al. (2005) reported that $17 \%$ of the 179 males and $11 \%$ of the 202 females surveyed illicitly used stimulant medication. This number was more than doubled in Low and Gendaszek's investigation of a small New England college with 35.5\% of the 150 students sampled reporting illicit use of legal amphetamines".
} 
vilégios para pessoas "especiais" ${ }^{4}$.

Nesse sentido, a compreensão do contexto de crescimento no uso de medicamentos/drogas (e seus mecanismos de legitimação) aponta para a direção da melhoria na identificação, prevenção e tratamento das doenças que fomentam a administração dessas substâncias ${ }^{75}$. Todavia, apesar das variadas denúncias sobre a mercantilização legitimadora dessas ações, tanto com publicações de entidades específicas da saúde ${ }^{76}$ quanto de jornais ${ }^{77}$, em princípio nada vem sendo proposto efetivamente para alteração do quadro delineado.

Cria-se assim um paradoxo no tratamento de usuários de drogas, o qual é devidamente orientado (seletividade) a partir dos parâmetros de classes sociais para atuação da intervenção penal ${ }^{78}$, onde aos mais baixos estratos se atua com coerção máxima (sem adentrar nas definições legais direcionadas) e aos mais altos se ignora totalmente. Porém, o quadro é pior do que a projeção geral, pois os usuários de drogas (ditas) lícitas, fazem uso, por vezes, para melhoria de desempenho (estimulantes) ${ }^{79}$, ou seja, patrocinam o modo de vida individualista e competitivo fruto da sociedade de consumo global, o que acaba por contribuir para sua imunização.

O que chama atenção na comparação entre usuários de drogas e suas variações é a forma de tratamento e a imagem projetada sobre cada um deles. Enquanto os mais pobres são relacionados à criminalidade e dependência, os mais ricos são associados a uma doença controlada ou mesmo à melhoria na qualidade de vida (ou no desempenho acadêmico/trabalho), embora o uso excessivo e a dependência possam ocorrer em quaisquer das duas linhas de adoção.

Isso posto, o cenário global parece inalterado e pouco preocupado com a

${ }_{74}$ CARVALHO, Salo de. A política criminal de drogas no Brasil (estudo criminológico e dogmático da Lei 11.343/06). 7. ed. São Paulo: Saraiva, 2014. p. 481.

${ }^{75}$ AMARI, Erica et al. Nonmedical Prescription Opioid Use and Mental Health and Pain Comorbidities: A Narrative Review. The Canadian Journal of Psychiatry, v. 56, n. 8, p. 495-502, August, 2011. p. 499.

${ }^{76}$ Nesse sentido está a publicação do National Institute of Mental Health. NATIONAL INSTITUTE OF MENTAL HEALTH. Global Use of ADHD Medications Rises Dramatically, 2007. Disponível em: < https://www. nimh.nih.gov/news/science-news/2007/global-use-of-adhd-medications-rises-dramatically.shtml > . Acesso em: 30 mar. 2018.

77 A publicação do New York Times Magazine expõe o consumo de drogas lícitas como um problema mais amplo, dimensionando como a "geração adderall". THE NEW YORK TIMES MAGAZINE. Generation Adderall: Like many of my friends, I spent years using prescription stimulants to get through school and start my career. Then I tried to get off them. Disponível em: < https://www.nytimes.com/2016/10/16/magazine/generation-adderall-addiction.html>. Acesso em: 30 mar. 2018.

${ }^{78}$ BUDÓ, Marília de Nardin. Mídias e discursos do poder: a legitimação discursiva do processo de encarceramento da juventude pobre no Brasil. Tese (Doutorado em Direito) - Universidade Federal do Paraná, Curitiba, 2013. p. 41.

79 DESANTIS, Alan D.; HANE, Audrey Curtis. "Adderall is definitely not a drug": Justifications for the illegal use of ADHD stimulants. Substance use $\&$ misuse, v. 45 , n. 1-2, p. 31-46, 2010. p. 41-42. 
imunização classista no consumo de drogas, e no plano nacional isso é igualmente referendado, pois inexiste qualquer diálogo sobre o assunto. Ante o exposto, enquanto o debate ocorre em outros países, no Brasil o silêncio significa a permissão legal e institucional para atuação combinada entre entes públicos e privados para o fornecimento de drogas para camadas especiais da população, as quais conforme se apresentaram aqui devem ser distinguidas de meros usuários de drogas. Esses últimos não se confundem, haja vista que além da falta de instrumentos legitimadores, também não possuem os mecanismos de ocultação do sistema penal, sendo "adequada" a sua persecução, ou ao menos é isso que se busca justificar com a atuação seletiva do sistema penal no tema das drogas.

\section{CONSIDERAÇÕES FINAIS}

O intuito do presente trabalho foi o de analisar os tratamentos seletivos no século XXI na política de drogas no Brasil. Teve como questionamento central verificar quais são mecanismos contemporâneos que garantem a manutenção da seletividade penal na política de drogas. Para isso, o primeiro item desse trabalho trata sobre a seletividade e discriminação social do sistema penal e da política de drogas a partir do marco teórico da criminologia crítica. Assim, foi apurado que o sistema penal e por consequência a política de drogas do país foram edificados a partir do racismo estrutural institucionalizado, derivados do colonialismo do país, formatando uma atuação profundamente seletiva e discriminatória.

A população negra tida como selvagem e predisposta a cometer ilícitos logo se tornaria alvo fácil do sistema coercitivo. Sem o mínimo de auxilio governamental após a abolição, obrigaram-se a viver à margem da sociedade branca civilizada. Essa questão histórica esclarece a hipossuficiência da população negra até os dias de hoje, bem como as relações de poder e os papéis que brancos e não brancos ocupam na sociedade atual.

Além disso, justifica os altos índices de negros e negras envolvidos com drogas dentro do sistema carcerário, considerando que a política de guerra às drogas no país tem função de invisibilização das desigualdades entre classes sociais. O que legitima a imposição de uma legislação penal seletiva originando novas formas de violências institucionais, que ditam as relações de poder dentro da sociedade. Dessa 
forma, nota-se que o racismo estrutural é ainda hoje um dos mecanismos que garantem a manutenção da seletividade penal na política de drogas.

Nesse sentido, em um segundo momento como forma de esmiuçar a temática também a partir da criminologia crítica, transpomos o objeto de estudo para os danos sociais, para que fosse possível uma visão macro sobre a temática de drogas. Assim, sendo possível visualizar danos sociais massivos que ficam ocultos a partir de um estudo meramente dogmático. Verificando que a criminalidade de colarinho branco (crimes dos poderosos), que ocasionam danos sociais massivos, ficam fora do campo coercitivo do sistema penal. Como, por exemplo, os lobbys, corrupção e negligências das indústrias farmacêuticas e relações mercadológicas entre Estado e corporações, evidenciando os interesses de classes sociais abastadas, enquanto aqueles marginalizados continuam reféns do sistema de forma reiterada, alimentando a máquina penal seletiva.

Diante disso, no último ponto do trabalho examina-se a diferenciação de tratamento dentro da política de drogas: doenças de castas e as corporações de drogas. Algo que ficou evidente diante da presente pesquisa, é que existe um maniqueísmo quando se trata da temática de drogas. Aqueles socialmente e estruturalmente marginalizados são sempre relacionados à dependência e à criminalidade, enquanto que os mais ricos são associados a uma doença que deve ser controlada por medicamentos ou que irá melhorar a sua qualidade de vida e desempenho, mesmo que o uso de drogas seja igualmente distribuído socialmente, abrangendo todos os grupos econômicos e sociais.

Posto isto, percorrendo o histórico-sociológico de desigualdades no país, verifica-se que os mecanismos que garantem a manutenção da seletividade penal na política de drogas estão arraigados de práticas do colonialismo e da proteção de classes sociais. O racismo estrutural ainda é evidente quando se trata de seletividade penal e relações de poder no Brasil, o jovem negro continua sendo identificado como aquele que comanda o tráfico de drogas, enquanto danos sociais ocasionados por grandes corporações como, por exemplo, os lobbys da indústria farmacêutica são invisibilizados, ao passo que a população pobre e negra serve de "bode expiatório" da manutenção da hierarquia racial no país. Ademais novos mecanismos de ocultação são utilizados para criar uma massa de usuários de drogas legalizadas e legitimadas (tanto por corporações quanto por profissionais), enquanto a grande massa pobre da população tem que lidar com os abusos do sistema penal. 


\section{REFERÊNCIAS}

AMARI, Erica et al. Non medical Prescription Opioid Use and Mental Health and Pain Comorbidities: A Narrative Review. The Canadian Journal of Psychiatry, v. 56, n. 8, p. 495-502, august, 2011.

ANDRADE, Vera Regina Pereira de. Pelas mãos da criminologia: o controle penal para além da (des)ilusão. Rio de Janeiro: Revan, 2012.

ARAÚJO, Carlos Eduardo Moreira de; SOARES, Carlos Eugenio Libano; GOMES, Flavio dos Santos; FARIAS, Juliana Barreto. Cidades negras: africanos, crioulos e espaços urbanos no Brasil escravista do século XIX. 2. ed. São Paulo: Alameda, 2006.

BANTON, Michael. A ideia de raça. São Paulo: Martins Fontes, 1991.

BARAK, Greg. The crimes of the powerful and the globalization of crime. Revista Brasileira de Direito. v. 11, n. 2, p. 104-114, jul./dez. 2015.

BARATTA, Alessandro. Criminologia crítica e crítica do direito penal: introdução à sociologia do direito penal. 3. ed. Rio de Janeiro: Revan/ICC, 2002.

BARATTA, Alessandro. Introducción a una sociología de la droga: problemas y contradicciones del controle penal de las drogodependencias. 1993. Disponível em: < http://www.alfonsozambrano.com/doctrina_penal/introduccion_sociologia_drogas.pdf. > . Acesso em: 07 mar. 2018.

BATISTA, Vera Malaguti. O Medo na cidade do Rio de Janeiro: dois tempos de uma história. 2. ed. Rio de Janeiro: Revan, 2003.

BECKER, Howard Saul. Outsiders: estudo de sociologia do desvio. Rio de Janeiro: Zahar, 2008.

BRAITHWAITE, John. Corporate crime in pharmaceutical industry. New York: Routledge, 2013.

BUDÓ, Marília de Nardin. Mídias e discursos do poder: a legitimação discursiva do processo de encarceramento da juventude pobre no Brasil. Tese (Doutorado em Direito) - Curso de Pós-Graduação em Direito, Universidade Federal do Paraná, Curitiba, 2013. 
BUDÓ, Marília de Nardin. Danos silenciados: a banalidade do mal no discurso científico sobre o amianto. Revista Brasileira de Direito, v. 12, n. 1, p. 127-140, jan./ jun. 2016.

CANTERJI, Rafael Braude. Política criminal e direitos humanos. Porto Alegre: Livraria do Advogado, 2008.

CARVALHO, Salo de. A política criminal de drogas no Brasil (estudo criminológico e dogmático da Lei 11.343/06). 7. ed. São Paulo: Saraiva, 2014.

CARVALHO, Salo de; DUARTE, Evandro Piza. Criminologia do preconceito: racismo e homofobia nas Ciências Criminais. São Paulo: Saraiva, 2017.

CASTRO, Fernando Borba de. Justiça Restaurativa: um olhar para além da repressão. Florianópolis: Empório do Direito, 2015.

CRUZ, Walter Firmo de Oliveira. Intoxicação e exclusão social. Revista da Associação Psicanalítica de Porto Alegre, Porto Alegre, n 24, 2003.

DESANTIS, Alan D.; HANE, Audrey Curtis. "Adderall is definitely not a drug": Justifications for the illegal use of ADHD stimulants. Substance use \& misuse, v. 45, n. 1-2, p. 31-46, 2010.

DURKHEIM, Émile. A divisão do trabalho social. 2. ed. São Paulo: Martins Fontes, 1999.

FERRAJOLI, Luigi. Direito e Razão: teoria do garantimo penal. 3. ed. São Paulo: Revista dos Tribunais, 2002.

FISCHER, Benedikt; ARGENTO, Elena. Prescription Opioid Related Misuse, Harms, Diversion and Interventions in Canada: A Review. Pain Physician Journal, n. 15, p. 191-203, 2012.

FLAUZINA, Ana Luiza Pinheiro. Corpo negro caído no chão: o sistema penal e o projeto genocida do estado brasileiro. Brasília, 2006. Dissertação de mestrado, Universidade de Brasília, 2006.

FREUD, Sigmund. O mal-estar na civilização. Rio de Janeiro: Imago, 1997. 
GÓES, Luciano. Racismo, genocídio e cifra negra: raízes de uma criminologia antropofágica. In: ANDRADE, Vera Regina Pereira de; CARVALHO, Gisele Mendes de; ÁVILA, Gustavo Noronha de. (Org.). Criminologias e Política Criminal. Florianópolis: CONPEDI, 2014.

HARVEY, David. 17 contradições e o fim do capitalismo. São Paulo: Boitempo, 2016.

INFOPEN. Levantamento Nacional de Informações penitenciárias. Disponível em: < http://depen.gov.br/DEPEN/depen/sisdepen/infopen/relatorio_2016_22-11. pdf $>$. Acesso em: 20 abr. 2018.

LASSLETT, Kristian. Crime or social harm? A dialectical perspective. Crime, Law and Social Change, v. 54, n. 1, p. 1-19, 2010.

LATOUCHE, Serge. O desafio do decrescimento. Tradução de António Viegas. Lisboa: Instituto Piaget, 2012.

LOMBROSO, Cesare. O homem delinquente. Porto Alegre: Rivardo Lens, 2001.

MAÍLLO, Alfonso Serrano. Introducción a la criminología. 6. ed. Madrid: Dynkinson, 2009.

MELMAN, Charles. Alcoolismo, delinquência, toxicomania: uma outra forma de gozar. São Paulo: Escuta, 2002.

MOHAMED, A. Rafik; FRITSVOLD, Erik D. Dorm Room Dealers: drugs and the Privileges of Race and Class. Boulder: Lynne Rienner Publishers, 2010.

NATALI, Lorenzo. Green criminology, victimización medioambiental y social harm. El caso de Huelva (España). Revista Crítica Penal y Poder, n. 7, p. 5-34, septiembre. 2014.

NATIONAL INSTITUTE OF MENTAL HEALTH. Global Use of ADHD Medications Rises Dramatically, 2007. Disponível em: < https:/www.nimh.nih.gov/news/science-news/2007/global-use-of-adhd-medications-rises-dramatically.shtml $>$. Acesso em: 30 mar. 2018. 
em: < http://www.globalcommissionondrugs.org/wpcontent/themes/gcdp_v1/pdf/ Global_Commission_Report_Portuguese.pdf>. Acesso em: 25 fev. 2016.

PIQUERO, Nicole Leeper; TIBBETTS, Stephen G.; BLANKENSHIP, Michael B. Examining the role of differential association and techniques of neutralization in explaining corporate crime. Deviant Behavior, n. 26, p. 159-188, 2005.

PIRES, Thula. Criminalização do Racismo: entre política de reconhecimento e meio de legitimação do controle social sobre os negros. Brasília: Brado Negro, 2016.

ROBINSON, Rowan. O grande livro da cannabis: guia completo de seu uso industrial, medicinal e ambiental. Rio de Janeiro: Zahar, 1999.

ROLIM, Marcos. A síndrome da rainha vermelha: policiamento e segurança pública no século XXI. 2. ed. Rio de Janeiro: Jorge Zahar, 2009.

ROSA, Alexandre Morais da; AMARAL, Augusto Jobim do. Cultura da punição: a ostentação do horror. 3. ed. Florianópolis: Empório do Direito, 2017.

ROSA, Pablo Ornelas. Drogas. In: CARLEN, Pat; FRANÇA, Leandro Ayres (Orgs.). Criminologias alternativas. Porto Alegre: Ciências Criminais, 2017.

RUBIO, David Sánchez; FRUTOS, Juan Antonio Senent de. Teoria crítica del derecho: nuevos horizontes. Sevilla: Centro de Estudios Jurídicos y Sociales Mispat, A.C., 2013.

SARMIENTO, Camilo Ernesto Bernal; CABEZAS, Sebastián; FORERO, Alejandro; RIVERA, Iñaki; VIDAL, Iván. Más allá de la criminología. Un debate epistemológico sobre el daño social, los crímenes internacionales y los delitos de los mercados. In: RIVERA, Iñaki (Coord.). Delitos de los Estados, de los Mercados y daño social: debates en criminología crítica y sociología jurídico-penal. Barcelona: Anthropos, 2014.

SUTHERLAND, Edwin H. White-collar criminality. American Sociological of Law, v. 5, n. 1, p. 1-12, february, 1940.

THE NEW YORK TIMES MAGAZINE. Generation Adderall: Like many of my friends, I spent years using prescription stimulants to get through school and start 
my career. Then I tried to get off them. Disponível em: < https://www.nytimes. com/2016/10/16/magazine/generation-adderall-addiction.html > . Acesso em: 30 mar. 2018.

TOMBS, Steve; WHYTE, David. La empresa criminal: porqué las corporaciones deben ser abolidas. Barcelona: Icaria, 2016.

WEIGERT, Mariana de Assis Brasil e. Uso de Drogas e Sistema Penal: entre o proibicionismo e a redução de danos. Rio de Janeiro: Lumen Juris, 2010.

ZAFFARONI, Eugenio Raúl. A palavra dos mortos: conferências de criminologia cautelar. São Paulo: Saraiva, 2012.

ZAFFARONI, Eugenio Raúl. Em busca das penas perdidas: a perda de legitimidade do sistema penal. Rio de Janeiro: Revan, 1991.

Recebido em: 23/04/2018 Aceito em: 28/09/2018 